\title{
Dengue serotyping with a label-free DNA sensor
}

Cite this: Anal. Methods, 2018, 10, 214

Received 5th September 2017

Accepted 25th November 2017

DOI: 10.1039/c7ay02131c

rsc.li/methods

\author{
S. K. Chan, ${ }^{a}$ Y. S. Choong, ${ }^{a}$ D. Perera ${ }^{b}$ and T. S. Lim (D) *ac
}

Dengue virus (DENV) is one of the most important mosquito-borne viruses in tropical and subtropical regions. Development of severe forms of dengue viral infection such as dengue fever (DF) and dengue hemorrhagic fever (DHF) has claimed many lives. The standard methods for detecting dengue virus are time consuming, laborious, and require skilful personnel. In this study, we propose a method whereby DENV RNA extracted from dengue infected mosquitoes was converted into DNA for probe hybridization to generate silver nanocluster strands that could be visualised under UV light. Label-free silver nanocluster based DNA sensors are able to provide strong fluorescence upon DNA hybridization. Highly specific DNA sequence detection is possible by taking advantage of the specificity of DNA hybridization kinetics. The proposed system is capable of detecting all four dengue DNA serotypes (DENV1-4) without any cross-reactivity. A single tube assay format showed better hybridisation efficiency with higher fluorescence intensity generated and a lower detection limit compared to a cocktail probe assay format. The method was able to detect as low as $100 \mathrm{nM}$ of amplified double stranded dengue DNA targets using both single and cocktail probe assays. This provides an interesting alternative approach for multiplex DNA sensing utilizing DNA silver nanoclusters as a reporter system.

\section{Introduction}

Dengue is regarded as a prevalent mosquito-borne viral disease in tropical and subtropical countries. ${ }^{1}$ Over the last few decades, dengue virus infections have increased at an alarming rate with 390 million dengue outbreaks estimated per year. ${ }^{2}$ The introduction of a new vaccine (Dengvaxia) against dengue infection has helped to reduce the concern of dengue infections but the vaccine has been reported to cause antibody dependent enhancement (ADE) raising concerns of its use. ${ }^{3}$ The spread of dengue beyond the traditional tropical and subtropical regions has been reported mainly due to the higher rate of human migration over the past decade. ${ }^{4}$ This infection is transmitted by mosquitoes mainly Aedes aegypti which can cause symptoms such as high fever, headache, stomach ache, rash, myalgia, and arthralgia. ${ }^{5}$ Only a small percentage of infected individuals will develop the severe form of dengue fever (DF) such as dengue hemorrhagic fever (DHF), or dengue shock syndrome (DSS) which are life-threatening. ${ }^{5,6}$ Early diagnosis in identifying the disease is key for patient management and the regulation of disease outbreak. ${ }^{7,8}$

${ }^{a}$ Institute for Research in Molecular Medicine, Universiti Sains Malaysia, 11800 Penang, Malaysia. E-mail: theamsoon@usm.my; Fax:+604-653-4803; Tel: +604-6534852

${ }^{b}$ Institute of Health \& Community Medicine, Universiti Malaysia Sarawak (UNIMAS), Kota Samarahan 94300, Malaysia

${ }^{c}$ Analytical Biochemistry Research Centre, Universiti Sains Malaysia, 11800 Minden, Penang, Malaysia

$\dagger$ Electronic supplementary information (ESI) available. See DOI: 10.1039/c7ay02131c
There are four dengue serotypes: DENV-1, 2, 3, and 4 . Infection with any of the four dengue serotypes confers lifelong immunity against the infected serotype. However, a subsequent infection with a different serotype might lead to a more severe infection due to ADE. ${ }^{9}$ Hence, DENV serotyping during the transmission season could serve as an imperative measure in epidemiological control of the disease. ${ }^{\mathbf{1 0}}$ The gold standard diagnosis for dengue infections involves the need to carry out virus isolation, viral antigen or genomic RNA detection, or virusspecific antibody detection. ${ }^{\mathbf{1 1 , 1 2}}$ Despite higher sensitivity and specificity, assays like virus isolation are laborious, time consuming, ${ }^{13}$ require trained personnel and are unsuitable for low titre virus samples. ${ }^{\mathbf{1 4}}$ In addition to this, viral RNA can only be detected 5 to 7 days after infection which often results in late diagnosis. ${ }^{15}$ Antibody detection in serum is a common method used to diagnose dengue infection due to its ease of handling. However, detection of antibodies is not possible at the early phase of infection due to low levels of IgM and IgG. ${ }^{\mathbf{1 6}}$ The NS1 strip test has been introduced to diagnose dengue infection rapidly via detection of dengue nonstructural protein 1 (NS1) by coating NS1 specific antibodies on test membranes. However, low sensitivity of NS1 detection has been reported in secondary infection due to the formation of immune complexes between NS1 antigen and existing antibodies. ${ }^{17}$

The advantage of RNA or cDNA detection systems for dengue over antibody or antigen assays is the ability to amplify the amount of RNA or cDNA available to detect samples at lower levels. These detection systems are faster, with improved sensitivity, and higher specificity. ${ }^{18-20}$ Several nucleic acid sensing methods for detecting DENV nucleic acid have been 
developed including loop-mediated isothermal amplification (LAMP) ${ }_{,}^{21}$ DNA microarrays, ${ }^{21}$ real-time PCR (qPCR), ${ }^{22}$ reverse transcriptase PCR (RT-PCR) $)^{23,24}$ and real-time reverse transcriptase PCR. ${ }^{25}$ Each method has its own set of advantages and disadvantages making alternative systems an intriguing prospect.

LAMP is able to detect DNA rapidly with high specificity and efficiency at a constant temperature. However, usually 4 to 6 primers are required to prime the specific regions for autocycling strand displacement of DNA. ${ }^{26}$ The DNA microarray assay is an interesting approach for high throughput screening of low level cDNAs in sera. However, extensive skills and knowledge are required for the fabrication and handling of DNA microarrays. ${ }^{27}$ Therefore, this technique is scarcely used for the detection of dengue virus. Real-time PCR (qPCR) and reverse transcriptase (RT) PCR are the two most commonly applied methods among nucleic acid sensing techniques due to their high specificity and sensitivity. ${ }^{28}$ Real-time PCR especially is reported to confer many advantages over conventional RT-PCR by offering high throughput screening, lower sample handling time, and the use of fluorescence based reporters. The only major setback of qPCR is the requirement of a specialised instrument and trained personnel to perform the assays. ${ }^{29}$ RTPCR also provides a rapid and sensitive method for DENV detection. However, detection of amplified DNA still requires secondary methods like integration of ethidium bromide in agarose gel, ${ }^{30}$ enzyme-linked immunosorbent assay, ${ }^{31}$ and labelled oligonucleotide probes for hybridisation. ${ }^{30}$

In this work, silver nanoclusters (AgNCs) were used as the readout indicator upon dengue gene amplification due to the attractive features of AgNCs. Silver nanoclusters were first reported by Dickson and his group showing the formation of AgNCs as a result of interactions between silver atoms and sequence specific single-stranded DNA (ssDNA). ${ }^{32}$ Silver ions are able to bind to the heterocyclic bases of DNA rather than the phosphate or sugar groups. This interaction induces a conformational change in DNA which decreases the DNA mobility in agarose gel. ${ }^{33}$ In addition to this, AgNCs are regarded as a noble metal nanocluster and a new class of fluorophores which exhibit a wide variety of attractive features. ${ }^{34}$ The synthesis of AgNCs is straightforward and produces a brighter fluorophore with good photostability. Moreover, the spectroscopic properties of AgNCs are tunable by adjusting the interaction between silver atoms and the DNA sequence as well as the DNA length. ${ }^{35}$ In comparison to other fluorescent labels such as organic dyes and quantum dots, AgNCs are an attractive alternative because AgNCs are brighter, smaller in size, and non-toxic. ${ }^{36}$ Recent publications highlighting the incorporation of AgNCs in DNA detection have been attracting wide interest. DNA detection using AgNCs mostly relies on analysing AgNC spectra shifts ${ }^{37}$ or "turn-on/turn-off" strategies..$^{38,39}$

Here, we describe a DNA detection probe system for dengue serotyping utilizing AgNC formation after target assisted isothermal exponential amplification (TAIEA). The targetbinding site of the probe was designed to complement the target dengue cDNA. The focus on utilizing DNA instead of RNA is due to the ease of sample handling, processing and mainly its resistance to degradation when compared to RNA.40,41 The probes were designed to hybridise specifically with the target dengue DNA to initiate isothermal amplification before the introduction of a nicking enzyme to promote the release of the AgNC forming strands. Optimization of the proposed system was performed using synthetic oligonucleotides, which was later tested with amplified dengue DNA samples. As low as $100 \mathrm{nM}$ of double stranded dengue DNA targets could be detected using both single and cocktail probe assays with fluorescence spectrometry. The proposed system was able to demonstrate specific detection of all four dengue serotypes.

\section{Experimental}

\subsection{Reagents and materials}

All oligonucleotides used were synthesized by Integrated DNA Technologies (IDT) (Lowa, US). The sequences of all synthesized oligonucleotides are shown in the ESI. $\uparrow$ Vent (exo-) DNA polymerase and Nt.BstNBI nicking enzyme were purchased from New England Biolabs (NEB) (Massachusetts, US). Sodium borohydride $\left(\mathrm{NaBH}_{4}\right)$ and silver nitrate $\left(\mathrm{AgNO}_{3}\right)$ were purchased from Fisher Scientific (Massachusetts, US).

\subsection{Preparation of dengue RNA samples}

DENV RNA was extracted from virus isolates obtained from clinical dengue cases. Serum samples from clinically diagnosed dengue patients were passaged through the C6/36 mosquito cell line. Samples were serially passaged for up to 3 passages or until the cytopathic effect (CPE) was observed. Then, the culture supernatant was harvested for DENV RNA extraction when greater than $80 \% \mathrm{CPE}$ was observed. The concentrations of RNA extracts were measured on a Nanodrop ${ }^{\mathrm{TM}} 2000 / 2000$ c spectro- $^{-}$ photometer (Thermo Fisher Scientific, Massachusetts, US). Sample collection was carried out in compliance with the laws and institutional guidelines approved by the Medical Research and Ethics Committee, Ministry of Health Malaysia. Informed consent for the use of the samples for the experiment was obtained from the donors.

\subsection{Preparation of dengue DNA samples}

Reverse transcription of dengue RNA samples into cDNA was done according to the manufacturer's protocol (SuperScript ${ }^{\mathrm{TM}}$ III Reverse transcriptase; Thermo Scientific Fisher, Massachusetts, US). A total of $2 \mu \mathrm{L}$ of cDNA product was used in subsequent PCR amplification. The resulting PCR product was then purified by ethanol precipitation and air-dried. The final product was resuspended in distilled water to a final volume of $10 \mu \mathrm{L}$ with distilled water. The concentration of the purified PCR product was measured using a Nanodrop ${ }^{\mathrm{TM}}$ 2000/2000c (Thermo Fisher Scientific, Massachusetts, US).

\subsection{Isothermal amplification}

The overall detection schematic for the target dengue sequence with the serotype specific probes is illustrated in Fig. 1. Firstly, $0.3 \mu \mathrm{M}$ of synthesised target dengue DNA was hybridised with $0.5 \mu \mathrm{M}$ dengue probe in $2 \mu \mathrm{L}$ of Buffer A $\left(25 \mathrm{mM}\right.$ Tris- $\mathrm{HNO}_{3}$ (pH 7.9), $50 \mathrm{mM} \mathrm{NaNO}, 5 \mathrm{mM} \mathrm{Mg}\left(\mathrm{NO}_{3}\right)_{2}$, and $0.5 \mathrm{mM}$ 


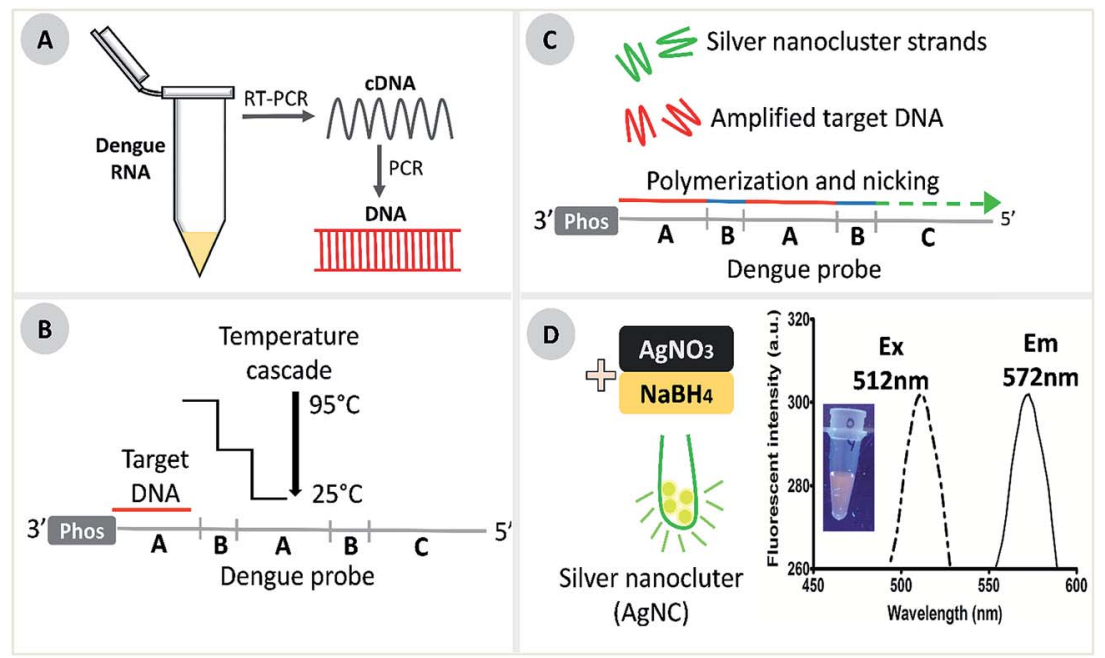

Fig. 1 Overall schematic representation of a label-free DNA sensor for dengue DNA detection. (A) Dengue RNA was first reverse transcribed into single stranded CDNA before PCR amplification to double stranded DNA. (B) Target DNA was hybridised with a probe using a temperature cascading program from $95^{\circ} \mathrm{C}$ to $25^{\circ} \mathrm{C}$. (C) Target DNA was extended by using DNA polymerase and nicked by using a nicking enzyme to release the amplified targets and silver nanocluster strands. (D) Incubation of silver nanocluster strands with $\mathrm{AgNO}_{3}$ followed by reduction with $\mathrm{NaBH}_{4}$ generates silver nanoclusters. Fluorescence spectra of silver nanoclusters used in this assay are based on the excitation wavelength at 512 nm and emission wavelength at $572 \mathrm{~nm}$.

dithiothreitol). The mixture was incubated with a temperature cascading program from $95{ }^{\circ} \mathrm{C}$ to $25{ }^{\circ} \mathrm{C}\left(95{ }^{\circ} \mathrm{C}, 80{ }^{\circ} \mathrm{C}, 70{ }^{\circ} \mathrm{C}\right.$, $50{ }^{\circ} \mathrm{C}$, $30{ }^{\circ} \mathrm{C}$, and $25{ }^{\circ} \mathrm{C}$ ) with each temperature point being maintained for 5 minutes (min). Then, $3 \mu \mathrm{L}$ of Buffer B $(10 \mathrm{mM}$ $\mathrm{NaNO}_{3}, 20 \mathrm{mM} \mathrm{NH} \mathrm{NO}_{3}, 20 \mathrm{mM}$ Tris- $\mathrm{HNO}_{3}, \mathrm{pH} 8.8,2 \mathrm{mM}$ $\mathrm{Mg}\left(\mathrm{NO}_{3}\right)_{2}$, and $0.1 \%$ Triton X-100), $1.5 \mu \mathrm{M}$ dNTPs, $0.17 \mathrm{U}$ Vent (exo-) DNA polymerase and $0.55 \mathrm{U}$ of Nt.BstNBI nicking enzyme were added to the mixture. Distilled water was added to the mixture to a final volume of $20 \mu \mathrm{L}$ and incubated at $55{ }^{\circ} \mathrm{C}$ for 5 hours (h) and stored at $4{ }^{\circ} \mathrm{C}$.

\subsection{Formation of silver nanoclusters}

The resulting isothermal amplification mixture was mixed with $200 \mu \mathrm{M}$ of $\mathrm{AgNO}_{3}$ and distilled water was added to a final reaction volume of $50 \mu \mathrm{L}$. The mixture was centrifuged at $12000 \mathrm{rpm}$ for $5 \mathrm{~min}$. The supernatant was then collected and incubated on ice in the dark for $15 \mathrm{~min}$. Then, $60 \mu \mathrm{M}$ of $\mathrm{NaBH}_{4}$ was freshly prepared and added to the mixture. The solution was incubated in the dark at room temperature (rt) for $1 \mathrm{~h}$.

\subsection{Visualization of the formation of silver nanoclusters}

The formation of AgNCs upon reduction with $\mathrm{NaBH}_{4}$ was determined using a fluorescence spectrophotometer (Agilent Varian Cary Ecplise, California, US). The excitation wavelength was set at $512 \mathrm{~nm}$ and the emission was expected to be in the range of $572 \mathrm{~nm}$. The excitation slit was set at $10 \mathrm{~nm}$ and the emission slit was set at $5 \mathrm{~nm}$.

\section{Results and discussion}

The design of the system for dengue DNA detection applies a similar concept of isothermal amplification to that published previously ${ }^{\mathbf{4 2}}$ with slight modifications, where the probe was designed with five regions denoted as 'ABABC' as shown in Fig. 1. Region A represents the region where the target dengue DNA hybridizes as the template for isothermal amplification. Hybridisation of the target to the probe was performed using a cascading temperature program from $95{ }^{\circ} \mathrm{C}$ to $25{ }^{\circ} \mathrm{C}$ (Fig. 1B). This would allow both the target oligonucleotides and probes to be denatured at $95{ }^{\circ} \mathrm{C}$ for the reduction of secondary structure formation. Reducing the temperature from $95{ }^{\circ} \mathrm{C}$ to $25{ }^{\circ} \mathrm{C}$ at a fixed rate will allow both target and probes to come to proximity for an improved percentage of successful hybridization.

Common practices for dengue diagnosis mainly surround the use of either RNA or DNA samples for detection. However, handling of the RNA sample is challenging due to the ease of RNA degradation over a short period of time which requires special and careful handling. ${ }^{\mathbf{4 3 , 4 4}}$ Therefore, although viral RNA is mainly obtained as the sample material, the conversion of RNA to cDNA was carried out prior to detection. This also allows the flexibility for on-site sample collection with rapid cDNA conversion for off-site analysis. This is a useful advantage when managing outbreaks in resource limited settings.

Upon hybridization, the target will serve as the primer for Vent (exo-) DNA polymerase to generate the complementary strand of the dengue probe as shown in Fig. 1C. The nicking enzyme (Nt.BstNBI) will then digest the oligonucleotide at the specific site denoted as ' $\mathrm{B}$ ' with a pre-defined sequence to release the target and AgNC strand that is complementary to sequence ' $\mathrm{C}$ '. The released target strand will then hybridize with another probe to repeat the similar process again. Successful amplification and generation of AgNC strands upon dengue target hybridisation was validated by agarose gel where the formation of a band similar to the AgNC band (Fig. 2A) could be observed. The formation of newly amplified AgNC strands is 


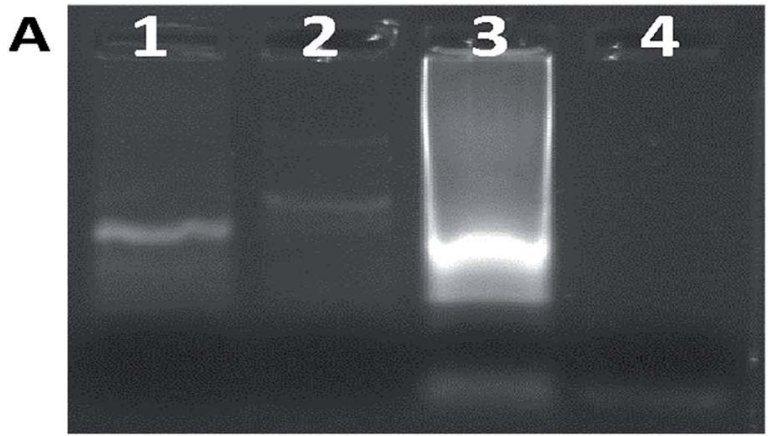

B i

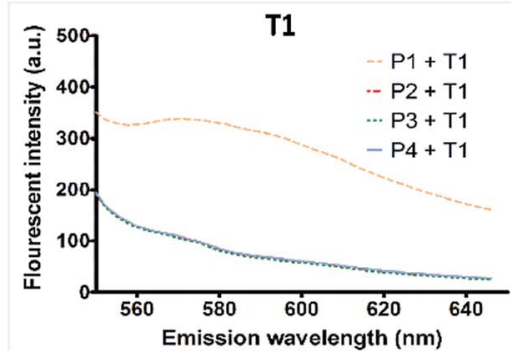

iii

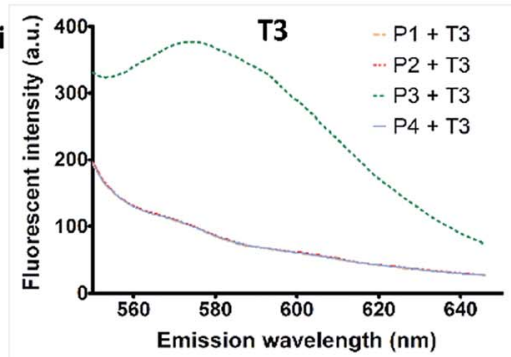

ii

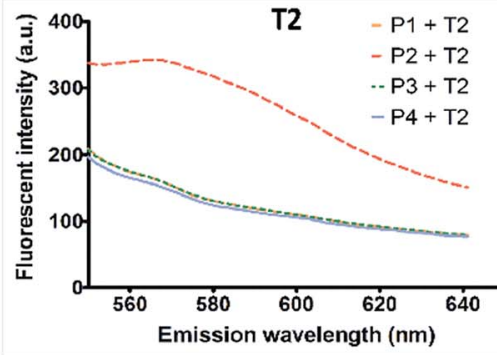

iv

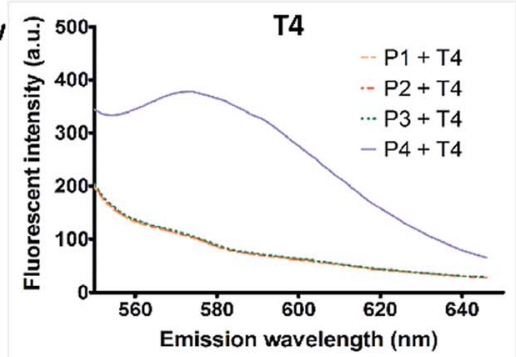

ii

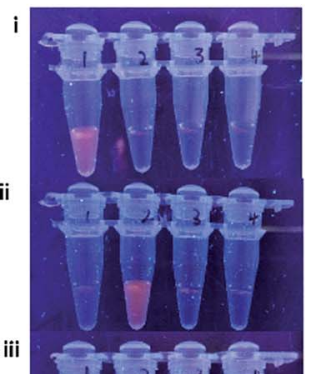

iii

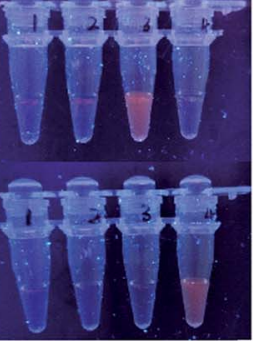

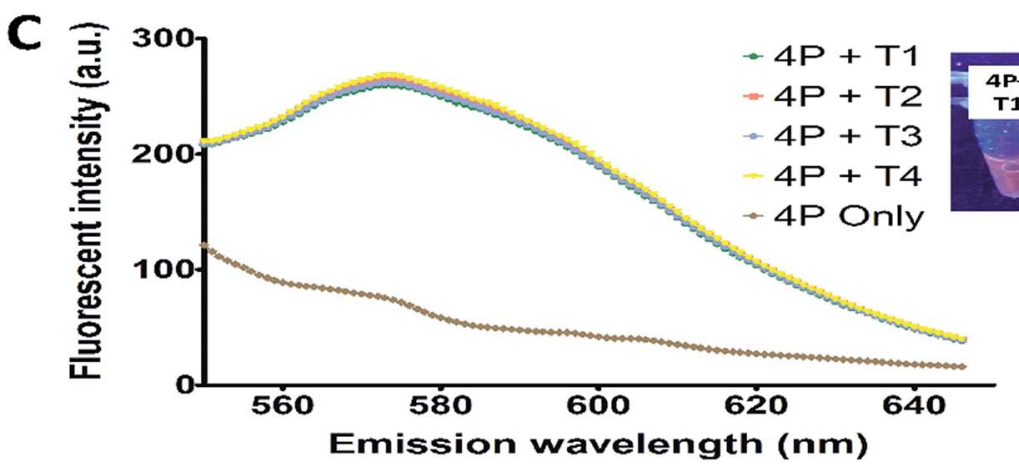

Fig. 2 Assay with synthetic target oligonucleotides. (A) Agarose gel analysis of silver nanocluster strand generation upon target hybridisation for DNA amplification and nicking. (B) Specificity of single probes was tested for cross-reaction with all four dengue serotypes. Inset shows only a specific target that binds to specific probe emitted fluorescence. (C) Cocktail probes were able to detect all four dengue serotypes.

observed from the agarose gel (Fig. 2A, Lane 3), which has a size similar to the positive control AgNC strand (Fig. 2A, Lane 4). Repeated cycles of amplification and nicking will eventually generate substantial amounts of AgNC strands that will directly influence the level of fluorescence under UV post-reduction with sodium borohydride $\left(\mathrm{NaBH}_{4}\right)$. Successful formation of AgNCs exhibits fluorescence emission at $572 \mathrm{~nm}$ upon excitation at $512 \mathrm{~nm}$. In this study, detection of the probe is based on the hybridisation of the target dengue DNA in region ' $\mathrm{A}$ '. The DNA was designed to target each dengue serotype specifically based on previously published sequences..$^{10}$ Hence, four probes (P1,
P2, P3, and P4) with sequence specific 'A' regions representing all four serotypes were designed for dengue serotyping by the generation of AgNC strands.

In this assay, incorporation of a label-free AgNC detection method allows for an alternative sensing approach for DENV serotyping. The ease of synthesis and non-toxic nature of AgNCs coupled with the improved photostability and brighter fluorescence readout compared to gold nanoclusters make AgNCs ideal for DNA sensing. ${ }^{36}$ Moreover the fluorescence emission of AgNC is tunable by DNA sequence programming. ${ }^{36,45-47}$ The application of AgNCs for diagnostics is not new with examples 
of them having been used in miRNA detection, ${ }^{\mathbf{4 2 , 4 6}}$ cell imaging, ${ }^{48}$ sensing, ${ }^{49,50}$ cell labelling, ${ }^{51}$ nucleic acid detection ${ }^{52,53}$ and drug delivery. ${ }^{54}$ The fluorescence intensity generated by AgNCs could be measured by using a fluorescence spectrophotometer since there is a direct correlation between the fluorescence intensity and AgNC concentration (Fig. S1†). The fluorescence intensity of AgNCs increases proportionally with an increase in AgNC concentration with a cut-off point at approximately $0.5 \mu \mathrm{M}$. This provides the basic working range of the AgNC for detection to be between $0.5 \mu \mathrm{M}$ and $3 \mu \mathrm{M}$ of AgNCs.

Optimization of the assay was carried out to obtain the best working conditions for the system as shown in Table S3 and Fig. S2. $\dagger$ Several factors were taken into consideration during optimization, such as incubation temperature, concentration of Vent (exo-) DNA polymerase, Nt.BstNBI nicking enzyme concentration, incubation time for amplification and nicking process, concentration of $\mathrm{NaBH}_{4}$ and concentration of silver nitrate $\left(\mathrm{AgNO}_{3}\right)$.

The optimum working temperature for Vent (exo-) DNA polymerase and Nt.BstNBI nicking enzyme was determined to be $75{ }^{\circ} \mathrm{C}$ and $55^{\circ} \mathrm{C}$ respectively. This is because Nt.BstNBI has a lower thermal stability compared to Vent (exo-) DNA polymerase. The Nt.BstNBI nicking activity is terminated at $80{ }^{\circ} \mathrm{C}$ due to protein denaturation. Hence, the optimum incubation temperature for this assay was determined to be within the range of $50{ }^{\circ} \mathrm{C}$ to $65{ }^{\circ} \mathrm{C}$. The incubation time was optimized to ensure that a maximum amount of product was generated from the template. Fig. S2B $\dagger$ demonstrates the effects of short incubation time on the amplification yield. The amount of DNA was seen to increase over time until a maximum yield at $5 \mathrm{~h}$, whereas the amount started to decrease at $6 \mathrm{~h}$. This decrease could be associated with the amount of dNTPs present that could be spent resulting in lower amounts of DNA being generated. This is expected, as a longer incubation time will ensure continuous amplification until all dNTPs are spent. The concentration of Vent (exo-) DNA polymerase and Nt.BstNBI was also optimized to ensure efficient use of the enzymes for improved amplification conditions. An insufficient amount of enzyme can result in lower yields while excess amounts of enzyme will result in an increased cost. It was likely that higher concentrations of the enzymes could also facilitate higher polymerization and nicking rates resulting in higher amounts of AgNC strands being formed. This could eventually lead to the formation of more AgNCs, which will yield higher fluorescence intensities. However, we found that an increase in enzyme concentrations beyond the optimum point did not influence the fluorescence intensity as it has reached a maximum output. Fig. S2C and $\mathrm{D} \dagger$ depict an increase in fluorescence intensities with an increase in enzyme concentration. The formation of AgNCs involves two vital components: $\mathrm{NaBH}_{4}$ and $\mathrm{AgNO}_{3}$. The ratio of these two components has always been fixed at $1: 6: 6$, $1: 12: 12$, or $1: 18: 18 .^{50,55-57}$ An equal molar ratio of $\mathrm{AgNO}_{3}$ and $\mathrm{NaBH}_{4}$ is always applied in the formation of AgNCs because one mole of $\mathrm{NaBH}_{4}$ is needed to reduce one mole of $\mathrm{AgNO}_{3}$ into silver atoms $\left(\mathrm{AgNO}_{3}+\mathrm{NaBH}_{4} \rightarrow \mathrm{Ag}+\mathrm{NaNO}_{3}+\frac{1}{2} \mathrm{~B}_{2} \mathrm{H}_{6}+\frac{1}{2} \mathrm{H}_{2}\right){ }^{58} \mathrm{In}$ this paper however, the molar ratio of $\mathrm{AgNO}_{3}$ was three times higher than that of $\mathrm{NaBH}_{4}$. Lower ratios were found to result in lower signals that were insufficient for detection. This is likely due to the tendency of silver ions from $\mathrm{AgNO}_{3}$ to bind proteins (DNA polymerase and nicking enzyme), similarly to the silverstaining concept of proteins in polyacrylamide gels. When the incubated product was centrifuged after $\mathrm{AgNO}_{3}$ addition, the silver ions were seen to bind to proteins and could be pelleted down at the bottom of the tube as shown in Fig. S3. $\dagger$ Hence, a higher molar ratio of $\mathrm{AgNO}_{3}$ to $\mathrm{NaBH}_{4}$ was applied to form AgNCs. In addition to this, certain salts such as chloride ions have also been reported to interfere with AgNC formation when present at high concentrations. ${ }^{59}$ Chloride ions have been shown to obstruct the formation of AgNCs via $\mathrm{AgCl}$ precipitation or the sequestering of silver ions. ${ }^{59}$ Hence, chloride ions were replaced with nitrate ions in the preparation of Buffer A and Buffer B for the assay to avoid such issues.

The optimized conditions for amplification were determined to be $55{ }^{\circ} \mathrm{C}$ for $5 \mathrm{~h}$ with $0.17 \mathrm{U}$ of Vent (exo-) DNA polymerase and $0.55 \mathrm{U}$ of Nt.BstNBI nicking enzyme. The optimized conditions for the formation of AgNCs were determined to be $200 \mu \mathrm{M}$ silver nitrate $\left(\mathrm{AgNO}_{3}\right)$ with $60 \mu \mathrm{M} \mathrm{NaBH} 4$. Under the optimized conditions, strong fluorescence readouts were generated within the correct emission wavelength.

The initial optimization for the detection system was performed using just one serotype. However, to ensure that the optimized conditions would apply to all the other serotypes, detection of the different targets by their specific probes was assessed individually. The cross-reactivity of the probes was investigated by incubating oligonucleotides with different dengue serotype sequences in competition. As shown in Fig. 2B and Table $\mathrm{S} 4 \mathrm{a}, \uparrow$ the designed probes were able to exhibit good specificity with no cross-reactivity upon incubation with competing sequences. The formation of AgNCs was not visible when detection was carried out using non-matching serotype sequence oligonucleotides to the serotype specific probes. When the serotype specific targets were introduced to the correct serotype probe pair, the formation of AgNCs was initiated. This resulted in an increase in fluorescence intensity for that particular sample. Therefore it is possible to apply the system for specific dengue detection and to an extent dengue serotyping. The dependence on specific DNA sequence hybridization in the system ensures low background readings and improved specificity.

The shelf life of AgNCs is greatly affected by their temporal stability which is largely correlated with the binding affinity of silver ions to DNA bases. ${ }^{\mathbf{6 0}, 61}$ Most AgNCs have short shelf lives due to the oxidation rates. ${ }^{62}$ The shelf life of AgNCs is crucial for the retention of fluorescence intensity over a certain period of time for detection especially when immediate documentation is not possible. Also, applications of highly stable AgNCs as biological labels that have a long shelf life are highly sought after. ${ }^{63-65}$ The fluorescence intensities of AgNCs generated from all dengue serotypes were determined from $2 \mathrm{~h}$ to 7 days. Fig. S $3 \uparrow$ demonstrates the increase in the fluorescence intensity of AgNCs after incubation in the dark for one day. The fluorescence intensity remained relatively stable up to 72 hours before it started to show signs of decrease. However, the 
fluorescence intensity is considered sufficiently high for detection even after 7 days denoting the stability of AgNCs generated.

Upon confirming that each probe was able to generate reporter strands with no cross-reactivity, the four probes were mixed in an equal ratio to produce a cocktail consisting of probes for all four serotypes. The single tube probe cocktail was evaluated for its ability to detect the presence of each synthesised serotype target sequence. Fig. 2C shows the successful detection of all four dengue serotypes using the probe cocktail. However, we did observe a slightly lower efficiency for detection using the probe cocktail compared to the single probe detection approach (Table $\mathrm{S} 4 \mathrm{~b} \dagger$ ). The drop in fluorescence could be attributed to the additional complexity associated with having four different probes in a single assay. This could have influenced the hybridisation efficiency to yield a lower fluorescence output but it did not interfere with the specificity of detection.

Both single probe and cocktail probe assays were later evaluated with detection of two dengue serotype targets concurrently. Reports of concurrent infections by more than one dengue serotype are not new due to the increasing occurrence of co-circulation of four dengue serotypes in the same area. ${ }^{\mathbf{1 9 , 6 6 , 6 7}}$ Concurrent DENV infections have led to severe dengue clinical manifestation. ${ }^{19,68}$ Fig. 3 demonstrates the detection of two dengue serotypes using both single probe and cocktail probe assays. DENV serotypes 2 and 3 were chosen here as a proof of concept due to the higher virulence with an increased likelihood to result in DHF outbreaks. ${ }^{69}$ Also, individuals infected with DENV serotype 2 or 3 usually experience silent infections. ${ }^{70,71}$ We found that both systems were able to detect the presence of the 2 serotypes at the same time. The cocktail probe assay was able to detect two serotypes in one tube format with a higher fluorescence intensity compared to the detection of a single serotype (Fig. 3A). However, the cocktail probe assay was unable to differentiate the DENV serotype present in the sample. The single probe assay on the other hand was able to identify the DENV serotype that was present in the sample, albeit with a lower fluorescence intensity (Fig. 3B).

The dengue specific probes are designed to detect dengue DNA specifically based on the variable region from the RNAdependent RNA polymerase (RdRp) domain that is highly conserved in flavivirus genomes. ${ }^{72-74}$ Hence it would be crucial for the probes to be able to differentiate between flaviviruses. Gene sequences from three different flaviviruses (JEV: Japanese Encephalitis Virus; YFV: Yellow Fever Virus; WNV: West Nile Virus) were synthesised to investigate the cross-reactivity of the dengue probes with other closely related flaviviruses. As demonstrated in Fig. S5, $\dagger$ the cocktail of dengue probes showed high specificity towards dengue DNA with no cross-reactivity with other tested flaviviruses.

We evaluated the proposed system by applying samples obtained from dengue virus cultures. Dengue RNA samples were first reverse transcribed to single stranded cDNA and later amplified with dengue RNA specific primers. All four dengue serotypes were successfully amplified as shown in Fig. 4A. These samples were later used as targets of the proposed system to generate AgNC strands. Amplified DNA showed that the single probe assay was able to detect the dsDNA amplified from all serotypes of the dengue RNA (Fig. 4B and Table $55 \dagger$ ), while the cocktail probe assay detection of amplified dengue DNA was not consistent among serotypes. Dengue serotype 1 appeared to hybridise better to the probes to give a higher fluorescence intensity compared to other serotypes. Dengue serotype 1 also showed the highest fluorescence intensity in the single probe assay. This is expected as dengue target serotype 1 has the lowest GC content and melting temperature $\left(T_{\mathrm{m}}\right)$ compared to other primers as demonstrated in Table S6. $\uparrow$ Hence, dengue target serotype 1 in dsDNA form has the lowest DNA duplex stability that requires the lowest temperature to dissociate into the ssDNA form compared to other dengue serotypes. The higher dissociation rate of duplex DNA into ssDNA enabled the dengue target gene to hybridise faster to the probe.

The detection limit of the proposed system was evaluated with DNA samples amplified from dengue virus RNA samples. Target DNA concentrations ranging from $0 \mathrm{nM}$ to $500 \mathrm{nM}$ were applied and the results are shown in Fig. 4C and D. The single probe assay showed better detection limits when compared to the cocktail probe assay. However, when the concentrations were reduced, both single probe and cocktail probe assays were unable to show clear differences in the generated fluorescence intensities. Overall, the fluorescence intensities could be
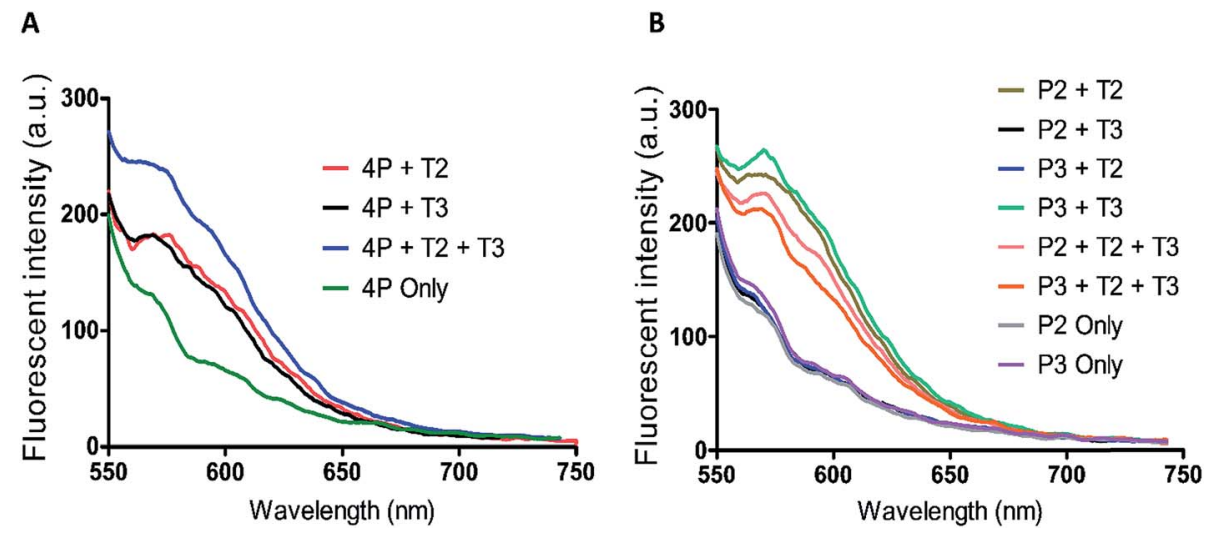

Fig. 3 Simultaneous detection of two dengue serotypes. (A) Single probe assay. (B) Cocktail probe assay. 

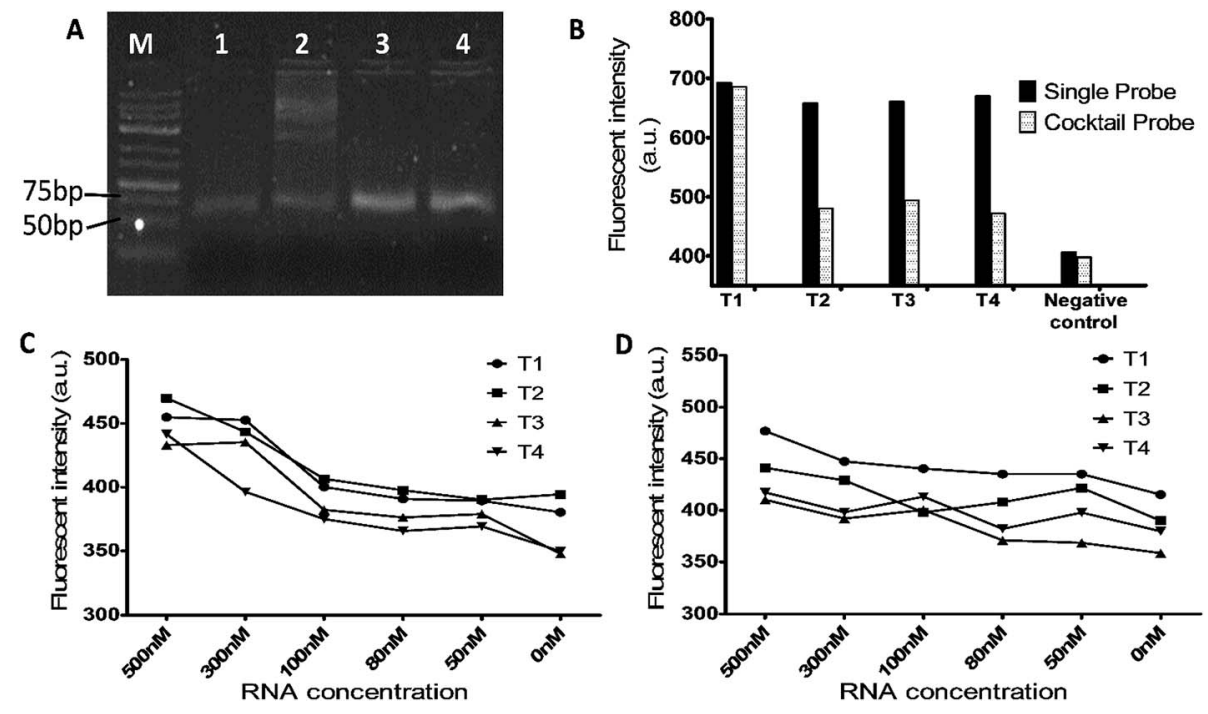

Fig. 4 Assay with dengue samples. (A) PCR amplification for all dengue serotypes. (B) Detection of amplified dengue DNA with both the single probe assay and the cocktail probe assay. (C) Limit of detection for amplified dengue DNA with the single probe assay. (D) Limit of detection for amplified dengue DNA with the cocktail probe assay.

discriminated between samples and controls at $100 \mathrm{nM}$ of target DNA using a fluorescence spectrophotometer.

\section{Conclusions}

The proposed method was able to hybridise dengue virus sequences for all serotypes successfully by isothermal amplification and nicking to generate sufficient reporter AgNC strands for DNA sensing. The formation of AgNC strands could be detected either by measuring the fluorescence intensity using a fluorescence spectrophotometer or by visualisation using a handheld UV lamp. Each serotype probe was able to detect its specific target and did not exhibit any cross-reactivity with probes of other serotypes. In order to have a single tube assay format, a multi-probe cocktail was used to determine the presence of dengue DNA sequences in the samples. The probe cocktail platform was able to detect the target DNA with good specificity but with a lower fluorescence intensity compared to single probe detection assays. Although the assay was able to differentiate four closely related DNA sequences specifically, we do not ignore the challenge of the assay as a result of the need for reverse transcription of dengue RNA before performing the assay. However, existing isothermal reverse transcription protocols can be adopted to overcome this shortcoming. In summary, the proposed platform provides an interesting alternative for DNA sensing using AgNCs for dengue serotyping. In addition to this, the ability of the assay to function as a single probe assay and multi-probe cocktail assay also adds an extra dimension to the assay as it can potentially function as a multiplex DNA assay for the detection of other various diseases.

\section{Conflicts of interest}

There are no conflicts to declare.

\section{Acknowledgements}

The authors would like to acknowledge support from the Malaysian Ministry of Higher Education through the Fundamental Research Grant Scheme (203/CIPPM/6711473) and Higher Institutions Centres of Excellence (HICoE) Grant Scheme (311/CIPPM/4401005). SKC would like to acknowledge the USM fellowship.

\section{Notes and references}

1 W. H. Organization, Global strategy for dengue prevention and control 2012-2020, World Health Organization, 2012.

2 S. Bhatt, P. W. Gething, O. J. Brady, J. P. Messina, A. W. Farlow, C. L. Moyes, J. M. Drake, J. S. Brownstein, A. G. Hoen and O. Sankoh, Nature, 2013, 496, 504-507.

3 M. Aguiar, N. Stollenwerk and S. B. Halstead, PLoS Neglected Trop. Dis., 2016, 10, e0005179.

4 E. A. Hunsperger, S. Yoksan, P. Buchy, V. C. Nguyen, S. D. Sekaran, D. A. Enria, J. L. Pelegrino, S. Vázquez, H. Artsob and M. Drebot, Emerging Infect. Dis., 2009, 15, 436-440.

5 A. T. Bäck and Å. Lundkvist, Infect. Ecol. Epidemiol., 2013, 3, 19839.

6 S. R. S. Hadinegoro, Paediatr. Int. Child Health, 2012, 32, 3338.

7 R. W. Peeling, H. Artsob, J. L. Pelegrino, P. Buchy, M. J. Cardosa, S. Devi, D. A. Enria, J. Farrar, D. J. Gubler and M. G. Guzman, Nat. Rev. Microbiol., 2010, 8, S30-S37.

8 P. Jahanshahi, E. Zalnezhad, S. D. Sekaran and F. R. M. Adikan, Sci. Rep., 2014, 4, 3851.

9 M. G. Guzmán, G. Kourí, L. Valdés, J. Bravo, S. Vázquez and S. B. Halstead, Bol. Of. Sanit. Panam., 2002, 11, 223-227. 
10 L.-J. Chien, T.-L. Liao, P.-Y. Shu, J.-H. Huang, D. J. Gubler and G.-J. J. Chang, J. Clin. Microbiol., 2006, 44, 1295-1304.

11 P.-Y. Shu and J.-H. Huang, Clin. Diagn. Lab. Immunol., 2004, 11, 642-650.

12 V. Vorndam, G. Kuno, D. Gubler and G. Kuno, Dengue and dengue hemorrhagic fever, CAB International, New York, NY, 1997, pp. 313-333.

13 A. Rathakrishnan and S. D. Sekaran, Expert Opin. Med. Diagn., 2013, 7, 99-112.

14 F. S. R. R. Teles, Anal. Chim. Acta, 2011, 687, 28-42.

15 D. H. Libraty, T. P. Endy, H.-S. H. Houng, S. Green, S. Kalayanarooj, S. Suntayakorn, W. Chansiriwongs, D. W. Vaughn, A. Nisalak and F. A. Ennis, J. Infect. Dis., 2002, 185, 1213-1221.

16 G. Yap, B. K. Sil and L.-C. Ng, PLoS Neglected Trop. Dis., 2011, 5, e1046.

17 A. Shrivastava, P. Dash, N. Tripathi, A. Sahni, N. Gopalan and P. L. Rao, Indian J. Med. Microbiol., 2011, 29, 51.

18 S.-J. L. Wu, E. M. Lee, R. Putvatana, R. N. Shurtliff, K. R. Porter, W. Suharyono, D. M. Watts, C.-C. King, G. S. Murphy and C. G. Hayes, J. Clin. Microbiol., 2001, 39, 2794-2798.

19 S. Lardo, Y. Utami, B. Yohan, S. M. Tarigan, W. D. Santoso, L. Nainggolan and R. T. Sasmono, Asian Pac. J. Trop. Med., 2016, 9, 134-140.

20 P. Chinnawirotpisan, M. Mammen, A. Nisalak, B. Thaisomboonsuk, S. Narupiti, V. Thirawuth, R. Putnak and C. Zhang, Arch. Virol., 2008, 153, 2225.

21 S.-f. Hu, M. Li, L.-l. Zhong, S.-m. Lu, Z.-x. Liu, J.-y. Pu, J.-s. Wen and X. Huang, BMC Microbiol., 2015, 15, 265.

22 Y. Y. Kong, C. H. Thay, T. C. Tin and S. Devi, J. Virol. Methods, 2006, 138, 123-130.

23 C. Klungthong, R. V. Gibbons, B. Thaisomboonsuk, A. Nisalak, S. Kalayanarooj, V. Thirawuth, N. Nutkumhang, M. P. Mammen and R. G. Jarman, J. Clin. Microbiol., 2007, 45, 2480-2485.

24 J. D. Callahan, S.-J. L. Wu, A. Dion-Schultz, B. E. Mangold, L. F. Peruski, D. M. Watts, K. R. Porter, G. R. Murphy, W. Suharyono and C.-C. King, J. Clin. Microbiol., 2001, 39, 4119-4124.

25 Y.-L. Lai, Y.-K. Chung, H.-C. Tan, H.-F. Yap, G. Yap, E.-E. Ooi and L.-C. Ng, J. Clin. Microbiol., 2007, 45, 935-941.

26 T. Notomi, H. Okayama, H. Masubuchi, T. Yonekawa, K. Watanabe, N. Amino and T. Hase, Nucleic Acids Res., 2000, 28, e63.

27 A. Díaz-Badillo, M. de Lourdes Muñoz, G. Perez-Ramirez, V. Altuzar, J. Burgueño, J. G. Mendoza-Alvarez, J. P. Martínez-Muñoz, A. Cisneros, J. Navarrete-Espinosa and F. Sanchez-Sinencio, Sensors, 2014, 14, 7580-7601.

28 E. Alm, G. Lindegren, K. I. Falk and N. Lagerqvist, $B M C$ Infect. Dis., 2015, 15, 493.

29 K. Gurukumar, D. Priyadarshini, J. Patil, A. Bhagat, A. Singh, P. Shah and D. Cecilia, Virol. J., 2009, 6, 1.

30 C. L. Lo, S. P. Yip, P. K. Cheng, T. S. To, W. W. Lim and P. H. Leung, Clin. Chem., 2007, 53, 594-599.
31 G. Chang, D. W. Trent, A. V. Vorndam, E. Vergne, R. M. Kinney and C. J. Mitchell, J. Clin. Microbiol., 1994, 32, 477-483.

32 J. Zheng and R. M. Dickson, J. Am. Chem. Soc., 2002, 124, 13982-13983.

33 Z. Yuan, Y.-C. Chen, H.-W. Li and H.-T. Chang, Chem. Commun., 2014, 50, 9800-9815.

34 J. T. Petty, J. Zheng, N. V. Hud and R. M. Dickson, J. Am. Chem. Soc., 2004, 126, 5207-5212.

35 J. T. Del Bonis-O'Donnell, S. Pennathur and D. K. Fygenson, Langmuir, 2016, 32, 569-576.

36 J. M. Obliosca, C. Liu, R. A. Batson, M. C. Babin, J. H. Werner and H.-C. Yeh, Biosensors, 2013, 3, 185-200.

37 S. Y. Lee, N. H. H. Bahara, Y. S. Choong, T. S. Lim and G. J. Tye, J. Colloid Interface Sci., 2014, 433, 183-188.

38 J.-L. Ma, B.-C. Yin, X. Wu and B.-C. Ye, Anal. Chem., 2016, 88, 9219-9225.

39 K. S. Park and H. G. Park, Biosens. Bioelectron., 2015, 64, 618624.

40 L. Buckingham, Molecular diagnostics: fundamentals, methods and clinical applications, FA Davis, 2011.

41 M. P. Deutscher, Nucleic Acids Res., 2006, 34, 659-666.

42 Y.-Q. Liu, M. Zhang, B.-C. Yin and B.-C. Ye, Anal. Chem., 2012, 84, 5165-5169.

43 Y.-W. Tang and C. W. Stratton, Advanced techniques in diagnostic microbiology, Springer, 2006.

$44 \mathrm{M}$. Fitzgerald-Hayes and F. Reichsman, DNA and Biotechnology, Academic Press, 2009.

45 T. Vosch, Y. Antoku, J.-C. Hsiang, C. I. Richards, J. I. Gonzalez and R. M. Dickson, Proc. Natl. Acad. Sci. U. S. A., 2007, 104, 12616-12621.

46 P. Shah, A. Rørvig-Lund, S. B. Chaabane, P. W. Thulstrup, H. G. Kjaergaard, E. Fron, J. Hofkens, S. W. Yang and T. Vosch, ACS Nano, 2012, 6, 8803-8814.

47 Y. Zhang, Y. Cai, Z. Qi, L. Lu and Y. Qian, Anal. Chem., 2013, 85, 8455-8461.

48 Y. Tao, Z. Li, E. Ju, J. Ren and X. Qu, Chem. Commun., 2013, 49, 6918-6920.

49 X. Liu, F. Wang, R. Aizen, O. Yehezkeli and I. Willner, J. Am. Chem. Soc., 2013, 135, 11832-11839.

50 J. Lee, J. Park, H. H. Lee, H. I. Kim and W. J. Kim, J. Mater. Chem. B, 2014, 2, 2616-2621.

51 J. Yu, S. Choi, C. I. Richards, Y. Antoku and R. M. Dickson, Photochem. Photobiol., 2008, 84, 1435-1439.

52 H.-C. Yeh, J. Sharma, J. J. Han, J. S. Martinez and J. H. Werner, Nano Lett., 2010, 10, 3106-3110.

53 W. Guo, J. Yuan, Q. Dong and E. Wang, J. Am. Chem. Soc., 2009, 132, 932-934.

54 A. K. Sahoo, U. Goswami, D. Dutta, S. Banerjee, A. Chattopadhyay and S. S. Ghosh, ACS Biomater. Sci. Eng., 2016, 2, 1395-1402.

55 Y. Teng, X. Yang, L. Han and E. Wang, Chem.-Eur. J., 2014, 20, 1111-1115.

56 M. Shamsipur, F. Molaabasi, S. Hosseinkhani and F. Rahmati, Anal. Chem., 2016, 88, 2188-2197.

57 M. R. C. Temboury, V. Paolucci, E. N. Hooley, L. Latterini and T. Vosch, Analyst, 2016, 141, 123-130. 
58 P.-C. Siqueira, W.-C. Ana-Paula-Rodrigues Magalhães, F.-C. P. Pires, E.-P. Silveira-Lacerda, M.-S. Carrião, A.-F. Bakuzis, C.-A. Souza-Costa, L.-G. Lopes and C. Estrela, J. Clin. Exp. Dent., 2015, 7, e622.

59 P. Shah, S. K. Cho, P. W. Thulstrup, Y.-J. Bhang, J. C. Ahn, S. W. Choi, A. Rørvig-Lund and S. W. Yang, Nanotechnology, 2014, 25, 045101.

60 L. Zhang and E. Wang, Nano Today, 2014, 9, 132-157.

61 M. Daune, C. Dekker and H. Schachman, Biopolymers, 1966, 4, 51-76.

62 S. Walczak, K. Morishita, M. Ahmed and J. Liu, Nanotechnology, 2014, 25, 155501.

63 C. M. Ritchie, K. R. Johnsen, J. R. Kiser, Y. Antoku, R. M. Dickson and J. T. Petty, J. Phys. Chem. C, 2007, 111, 175-181.

64 J. Sharma, H.-C. Yeh, H. Yoo, J. H. Werner and J. S. Martinez, Chem. Commun., 2010, 46, 3280-3282.

65 S. Choi, J. Yu, S. A. Patel, Y.-L. Tzeng and R. M. Dickson, Photochem. Photobiol. Sci., 2011, 10, 109-115.
66 M. N. Reddy, R. Dungdung, L. Valliyott and R. Pilankatta, PeerJ, 2017, 5, e2970.

67 P. Bharaj, H. S. Chahar, A. Pandey, K. Diddi, L. Dar, R. Guleria, S. K. Kabra and S. Broor, Virol. J., 2008, 5, 1.

68 W. M. Hammon, Am. J. Trop. Med. Hyg., 1973, 22, 82-91.

69 J. R. Fried, R. V. Gibbons, S. Kalayanarooj, S. J. Thomas, A. Srikiatkhachorn, I.-K. Yoon, R. G. Jarman, S. Green, A. L. Rothman and D. A. Cummings, PLoS Neglected Trop. Dis., 2010, 4, e617.

70 M. G. Guzman, A. Alvarez, S. Vazquez, M. Alvarez, D. Rosario, O. Pelaez, G. Cruz, R. Rodriguez, A. Pavon and A. Gonzalez, Int. J. Infect. Dis., 2012, 16, e198-e203.

71 M. G. Guzmán, G. Kouri, L. Valdes, J. Bravo, M. Alvarez, S. Vazques, I. Delgado and S. B. Halstead, Am. J. Epidemiol., 2000, 152, 793-799.

72 G. Kuno, J. Virol. Methods, 1998, 72, 27-41.

73 G. Kuno, G.-J. J. Chang, K. R. Tsuchiya, N. Karabatsos and C. B. Cropp, J. Virol., 1998, 72, 73-83.

74 N. Scaramozzino, J.-M. Crance, A. Jouan, D. A. DeBriel, F. Stoll and D. Garin, J. Clin. Microbiol., 2001, 39, 1922-1927. 